\title{
Effects of rTMS of Pre-Supplementary Motor Area on Fronto Basal Ganglia Network Activity during Stop-Signal Task
}

\author{
Takamitsu Watanabe, ${ }^{1,4}$ Ritsuko Hanajima, ${ }^{2}$ Yuichiro Shirota, ${ }^{2}$ Ryosuke Tsutsumi, ${ }^{2}$ Takahiro Shimizu, ${ }^{2}$ \\ Toshihiro Hayashi, ${ }^{2}$ Yasuo Terao, ${ }^{2}$ OYoshikazu Ugawa, ${ }^{5,6}$ Masaki Katsura, ${ }^{3}$ Akira Kunimatsu, ${ }^{3}$ Kuni Ohtomo, ${ }^{3}$ \\ Satoshi Hirose, ${ }^{1,7}$ Yasushi Miyashita, ${ }^{1}$ and Seiki Konishi ${ }^{1,7}$ \\ Departments of ${ }^{1}$ Physiology, ${ }^{2}$ Neurology, and ${ }^{3}$ Radiology, The University of Tokyo School of Medicine, Bunkyo-ku, Tokyo 113-0033, Japan, ${ }^{4}$ Institute of \\ Cognitive Neuroscience, University College London, London WC1N 3AR, United Kingdom, ${ }^{5}$ Department of Neurology, School of Medicine, Fukushima \\ Medical University, Fukushima 960-1247, Japan, ${ }^{6}$ Research Seeds Program, Japan Science and Technology Agency, Fukushima 960-1247, Japan, and \\ ${ }^{7}$ Department of Physiology, Juntendo University School of Medicine, Bunkyo-ku, Tokyo 113-8421, Japan
}

Stop-signal task (SST) has been a key paradigm for probing human brain mechanisms underlying response inhibition, and the inhibition observed in SST is now considered to largely depend on a fronto basal ganglia network consisting mainly of right inferior frontal cortex, pre-supplementary motor area (pre-SMA), and basal ganglia, including subthalamic nucleus, striatum (STR), and globus pallidus pars interna (GPi). However, causal relationships between these frontal regions and basal ganglia are not fully understood in humans. Here, we partly examined these causal links by measuring human fMRI activity during SST before and after excitatory/inhibitory repetitive transcranial magnetic stimulation (rTMS) of pre-SMA. We first confirmed that the behavioral performance of SST was improved by excitatory rTMS and impaired by inhibitory rTMS. Afterward, we found that these behavioral changes were well predicted by rTMSinduced modulation of brain activity in pre-SMA, STR, and GPi during SST. Moreover, by examining the effects of the rTMS on restingstate functional connectivity between these three regions, we showed that the magnetic stimulation of pre-SMA significantly affected intrinsic connectivity between pre-SMA and STR, and between STR and GPi. Furthermore, the magnitudes of changes in resting-state connectivity were also correlated with the behavioral changes seen in SST. These results suggest a causal relationship between pre-SMA and GPi via STR during response inhibition, and add direct evidence that the fronto basal ganglia network for response inhibition consists of multiple top-down regulation pathways in humans.

Key words: partial correlation; QPS; response cancellation; response inhibition

\section{Introduction}

The stop-signal task (SST; Logan and Cowan, 1984) has been used in investigations of neural mechanisms underlying response inhibition (Aron et al., 2003; Rubia et al., 2003; Chambers et al., 2006; Li et al., 2006; Chikazoe et al., 2009). In the task, participants must inhibit their already initiated responses when they encounter occasional stop signals (Fig. $1 A$ ).

The successful response inhibition is now considered to depend mainly on the activity of right inferior frontal cortex (rtIFC), pre-supplementary motor area (pre-SMA), and basal ganglia including subthalamic nucleus (STN), striatum (STR),

Received Sept. 9, 2014; revised Feb. 2, 2015; accepted Feb. 9, 2015

Author contributions: T.W., Y.M., and S.K. designed research; T.W., R.H., Y.S., R.T., T.S., T.H., Y.T., M.K., A.K., S.H., and S.K. performed research; T.W. analyzed data; T.W., Y.U., K.O., Y.M., and S.K. wrote the paper.

This work was supported by the Japan Society for Promotion of Science (T.W.). The work was also supported by a grant from the Uehara Memorial Foundation, and Grants-in-Aid for Scientific Research B (22300134) to S.K. and (25293206) to Y.U.

The authors declare no competing financial interests.

Correspondence should be addressed to either of the following: Takamitsu Watanabe, Institute of Cognitive Neuroscience, University College London, 17 Queen Square, London WC1N 3AR, UK, E-mail: takamitsu.watanabe@ucl.ac.uk; or Seiki Konishi, Department of Physiology, Juntendo University School of Medicine, 2-1-1 Hongo, Bunkyo-ku, Tokyo 113-8421, Japan. E-mail: skonishi@juntendo.ac.jp.

DOI:10.1523/JNEUROSCI.3761-14.2015

Copyright $\odot 2015$ the authors $\quad 0270-6474 / 15 / 354813-11 \$ 15.00 / 0$ and globus pallidus pars interna (GPi). For example, a line of studies has reported that inhibition performance was affected by a chronic or temporal lesion in rtIFC (Aron et al., 2003; Chambers et al., 2007; Verbruggen et al., 2010; Obeso et al., 2013; Zandbelt et al., 2013) and pre-SMA (Floden and Stuss, 2006; Nachev et al., 2007; Chen et al., 2009; Hsu et al., 2011; Cai et al., 2012; Obeso et al., 2013).

Neuroimaging research has also shown that successful inhibition was accompanied by increases in the activity of rtIFC (Aron and Poldrack, 2006; Aron et al., 2007; Zheng et al., 2008; Cai and Leung, 2009; Swann et al., 2009, 2013; Chatham et al., 2012), pre-SMA (Aron and Poldrack, 2006; Aron et al., 2007; Tabu et al., 2011; Swann et al., 2012; Cai et al., 2014), STN (Aron and Poldrack, 2006; Aron et al., 2007; Isoda and Hikosaka, 2008; Li et al., 2008; Chatham et al., 2012; Ray et al., 2012; Alegre et al., 2013), and GPi (Aron and Poldrack, 2006; Schmidt et al., 2013). Moreover, STR and STN are supposed to directly receive and transmit cortical inputs to more downstream neurons (Albin et al., 1989; Alexander and Crutcher, 1990; Nambu et al., 2002; Hikosaka and Isoda, 2010; Aron et al., 2014).

As a whole, these findings indicate that a fronto basal ganglia network consisting of these five regions supports the successful response inhibition in SST (Nambu et al., 2002; Voytek, 2006; 
A

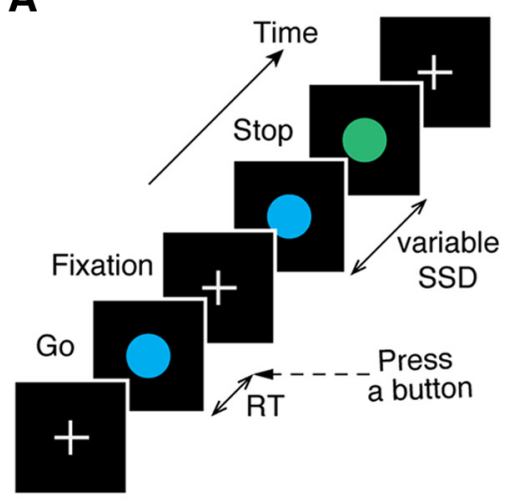

B

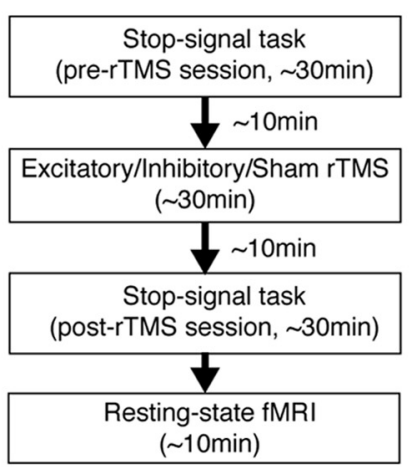

C

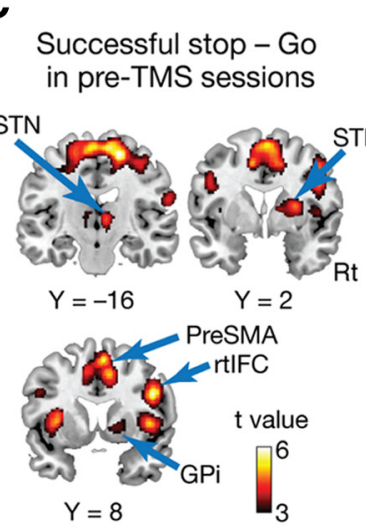

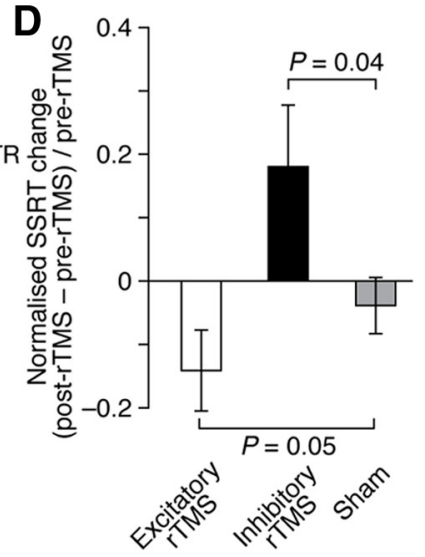

Figure 1. Experiment design and behavioral results. A, SST. Participants underwent a standard SST. In most trials, go signals appeared, and participants were instructed to quickly press a button. Occasionally, a stop signal appeared after a go signal, in which participants must withhold the button press. $\boldsymbol{B}$, Overall experiment design. Participants underwent three types of rTMS conditions with at least a 1 week interval: excitatory, inhibitory, and sham rTMS conditions. They first conducted SST in an fMRI scanner (pre-rTMS session) before each rTMS conditioning. They then performed another SST and underwent a resting-state fMRI recording (post-rTMS session). C, ROIs. Five ROIs were determined based on a brain activation map contrasting successful stop and go trials with fMRI activity during pre-rTMS sessions (Table 1). Rt, Right. D, Behavioral results. SSRT was reduced by the excitatory rTMS (i.e., improvement of response inhibition) and was prolonged by the inhibitory

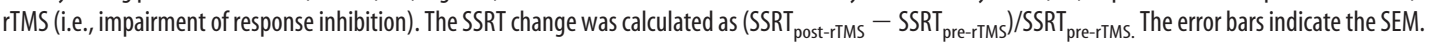

Chambers et al., 2009; Hikosaka and Isoda, 2010; Juan and Muggleton, 2012; Aron et al., 2014).

However, some parts of the causal connections in the network remain unclear. In particular, functional influences of pre-SMA on this functional network are elusive in humans (Aron et al., 2014). Recent studies using repetitive transcranial magnetic stimulation (rTMS) have suggested that rtIFC activity is tightly associated with pre-SMA activity (Neubert et al., 2010), and that, in concert with rtIFC, pre-SMA sharpens the selectivity of motor activation and facilitates inhibitory motor control (Duque et al., 2013). Despite these notable advances, it is still controversial whether pre-SMA can induce response inhibition without rtIFC activity, or is simply activated after rtIFC activation (Duann et al., 2009; Swann et al., 2012).

Here, we aimed at directly examining this causal influence of pre-SMA on the fronto basal ganglia network by probing brain activity changes after administering rTMS of the region. To focus on the effects on the network, we analyzed the activity of the five functionally defined constituent regions (rtIFC, pre-SMA, STN, STR, and GPi).

\section{Materials and Methods}

Participants. Ten healthy, adult, right-handed male volunteers (28-44 years old) participated in the current study after providing their written informed consent. None of them had any neurological, psychiatric, other medical problems, or contraindications to TMS (Wassermann, 1998; Rossi et al., 2009). The procedure of rTMS complied with the guidelines for TMS experimentation on humans (Drummond, 2009), and the fMRI and rTMS procedures were approved by the Institutional Review Board of the School of Medicine, The University of Tokyo. Because 1 of the 10 participants could not complete the entire experimental protocol due to his relocation, we analyzed data obtained from the remaining 9 participants.

Overall design. To induce long-lasting changes in brain activity, we used quadripulse rTMS (QPS), the effects of which are supposed to continue for a relatively long time after the stimulation $(\sim 30 \mathrm{~min}$ to $2 \mathrm{~h}$; Hamada et al., 2007, 2008; Shirota et al., 2010; Nakamura et al., 2011; Nakatani-Enomoto et al., 2012; Watanabe et al., 2014).

Each participant underwent the following three types of experimental conditions, with interval of $>1$ week: excitatory, inhibitory, and sham rTMS. In all, the participants first performed SST in an fMRI scanner $(\sim 30 \mathrm{~min})$, and afterward received one type of rTMS of pre-SMA $(\sim 30$ min; Fig. $1 B)$. Immediately after the stimulation $(\sim 10 \mathrm{~min})$, they conducted another SST in the fMRI scanner ( $\sim 30 \mathrm{~min})$. Resting-state fMRI
(rsfMRI) signals were recorded immediately after the post-rTMS SST $(\sim 10 \mathrm{~min})$. The order of the three rTMS conditions was pseudorandomized and counterbalanced across participants. The participants were blind to the types of the stimulus they were receiving. The intensity and location of rTMS were individually determined before the beginning of the entire experiment.

In the analysis, we assessed rTMS-induced behavioral/neural effects by comparing changes observed in the real rTMS conditions with those observed in the sham condition. The current experiment design contained an $\sim 1$ h gap between pre-rTMS and post-rTMS SST sessions, which itself could affect behaviors and brain activity responses (e.g., tiredness might deteriorate individual attention, and worsen behavioral and neural responses during the SST). To minimize such confounding, we adopted the differences in responses between pre-rTMS and postrTMS sessions in the sham condition as the baseline level.

rTMS procedures. Individual parameters of rTMS were determined through prior single-pulse TMS experiments with a hand-held figure-ofeight coil (9 cm external diameter at each wing; Magstim Co., Ltd.). We measured the active motor threshold (AMT) for the right first dorsal interosseous (FDI) muscle, which was defined as the lowest intensity that evoked a small response $(>100 \mu \mathrm{V})$ when participants maintained a slight contraction of the right FDI $(\sim 10 \%$ of the maximum voluntary contraction) in $>5$ of 10 consecutive trials. The intensity of rTMS in the main experiment was set at $90 \%$ of AMT. The mean ( \pm SEM) AMT across participants was $37.5 \pm 7.2 \%$ maximum stimulator output.

The FDI response [i.e., motor evoked potentials (MEPs) of the FDI] was recorded with pairs of $\mathrm{Ag} / \mathrm{AgCl}$ surface cup electrodes $(9 \mathrm{~mm}$ in diameter) placed over the muscle belly (active) and the metacarpophalangeal joint of the index finger (reference; Hanajima et al., 2001). The signals recorded by the electrodes were input to an amplifier (Biotop, GE Marquette Medical Systems) through filters that were set at $100 \mathrm{~Hz}$ and 3 $\mathrm{kHz}$, and, after digitization, were stored on a computer for later off-line analyses (TMS BiStim tester, Medical Try System). The optimal site for brain stimulation for the right FDI muscle was individually determined as the area eliciting the largest MEP.

Using this predetermined intensity, we performed quadripulse rTMS, which consisted of a train of four monophasic magnetic pulses, and was delivered with four magnetic stimulators connected to a specially designed combining module (Magstim 2002, Magstim Co., Ltd.). The interburst interval was set at $5 \mathrm{~s}$. One rTMS block had 360 consecutive bursts, each of which comprised four magnetic pulses separated by interstimulus intervals of 5 or $50 \mathrm{~ms}$, respectively, for excitatory or inhibitory rTMS. Sham stimulations were conducted with the two sets of figure-ofeight coils. One set was placed right behind the participants but was concealed from the participants' view. This figure-of-eight coil was con- 
nected to the same TMS machine and was activated at $200 \mathrm{~Hz}$ during the sham condition to produce acoustic effects that were comparable to those during the real rTMS. The other coil set was unconnected to the stimulation settings, which was kept blind for the participants. This coil was held over the same position of the head as the real rTMS.

Based on our previous study (Chikazoe et al., 2009), the coordinates of the stimulated site (i.e., pre-SMA) were set at $[6,6,62]$ in Montreal Neurological Institute (MNI) coordinates. We determined the site for each participant using an individual anatomical brain image: the individual images were first normalized to a standard image with a linear normalization algorithm implemented in SPM software (www.fil.ion. ucl.ac.uk/spm/). Based on an inverse of the transforming matrix optimized in the linear normalization, we then calculated the original coordinates corresponding to $[6,6,62]$ in MNI coordinates and marked the site on the individual non-normalized brain image. Finally, using the mark as a guide, we determined the target site on the individual head with a frameless stereotactic optical tracking neuronavigation system (Brainsight, Rogue Research).

Stop-signal task. The current SST conventionally consisted of "go," "stop," and fixation trials (Logan and Cowan, 1984; Aron et al., 2003; Fig. $1 A)$. In the fixation trials ( $1.7 \mathrm{~s})$, participants were instructed to pay attention to a small cross on the center of the screen. After the fixation trial, they were presented with a circle in $\sim 2.5^{\circ} \times 2.5^{\circ}$ of visual angle. In go trials, the color of the circle did not change, and participants were required to quickly press a button during the trials with the right index finger; the circle vanished at the button press or after $800 \mathrm{~ms}$ elapsed, and the trial terminated. In stop trials, the color of the circle changed to a different one after a so-called stop-signal delay (SSD); participants were asked to withhold the button press. The trials were terminated by mistakenly pressing the button or at $800 \mathrm{~ms}$ after the appearance of the stop signal. The SSD varied from one stop trial to the next one according to a staircase procedure (initial SSD, $200 \mathrm{~ms}$; Band et al., 2003): when participants successfully withheld their response, the SSD increased by $33 \mathrm{~ms}$; if they failed, the SSD decreased by $33 \mathrm{~ms}$. The number of stop trials was set at $20 \%$ of the entire number of trials, and they appeared in a pseudorandom order. The fixation trials were inserted between each go/stop trial.

The participants were instructed to quickly respond to go signals but were also asked to keep in mind that occasional stop signals could appear. Before the fMRI scanning, the participants underwent a sufficient number of practice trials. In each of the pre-rTMS and post-rTMS sessions, participants completed six SST runs, each of which continued for $3 \mathrm{~min}$ and consisted of $72.1 \pm 12.5$ trials (across all the participants and recorded experiments). The colors of go/stop signals (blue/green) were counterbalanced across the participants.

Behavioral analysis. The behavioral performance of the SST was quantified as the stop-signal reaction time (SSRT; Logan and Cowan, 1984; Congdon et al., 2012). First, we ranked reaction time (RT) for go trials, and selected the Nth RT (representative RT), where $N$ was calculated by multiplying the number of stop trials by the probability of mistakes in stop trials. We then estimated SSRT through subtraction of the average SSD from the representative RT. The rTMS-induced changes in SSRT were evaluated as $\left(S_{S R T}\right.$ post-rTMS $-S_{\text {SRT }}$ pre-rTMS $) / S S R T_{\text {pre-rTMS. }}$

fMRI scanning and analysis. MRI scanning was performed with a $3 \mathrm{~T}$ MRI scanner with a one-channel head coil (Signa HDxt 3.0T, GE Healthcare). T1-weighted structural images were obtained as the anatomical reference $\left(0.81 \times 0.81 \times 1.20 \mathrm{~mm}^{3}\right)$, whereas functional images were obtained using gradient echo echoplanar sequences ( $\mathrm{TR}=3 \mathrm{~s}$; TE $=35$ $\mathrm{ms}$; flip angle $=90^{\circ} ; 3 \times 3 \times 3 \mathrm{~mm}^{3} ; 40$ slices). The first five functional images in each run were discarded to minimize the effects of transient magnetic saturation.

The functional images were first realigned, slice timing corrected, normalized to the default template with interpolation to a $2 \times 2 \times 2 \mathrm{~mm}^{3}$ space, and spatially smoothed [full-width at half-maximum (FWHM), 8 $\mathrm{mm}$, Gaussian filter] using SPM8 software. The preprocessed data were submitted to single-level analysis based on a general linear model, into which three types of event timing ("go," "successful stop," and "failed stop" trials) were coded using the canonical hemodynamic function. We separately performed this single-level analysis for pre-rTMS/post-rTMS
Table 1. Stop-related regions: successful stop - go trials in pre-TMS sessions

\begin{tabular}{llrrrr}
\hline & & \multicolumn{3}{c}{ MNI coordinates } & \\
\cline { 3 - 5 } Anatomical label & Hemisphere & \multicolumn{1}{c}{$x$} & \multicolumn{1}{c}{$\boldsymbol{y}$} & t value \\
\hline rtIFC & Right & 48 & -16 & 24 & 5.9 \\
Pre-SMA & Right & 6 & 8 & 58 & 5.4 \\
STN & Right & 8 & -16 & 0 & 4.7 \\
STR & Right & 24 & 2 & 8 & 4.6 \\
GPi & Right & 18 & 6 & 0 & 3.2 \\
\hline
\end{tabular}

sessions, and estimated inhibition-related brain activity by contrasting successful stop and go trials or contrasting successful stop and failed stop trials.

ROI definition. In the main analysis, we functionally defined regions of interest (ROIs) based on fMRI activity during pre-rTMS sessions. For precise and robust determination, we searched for the brain activations in successful stop versus go contrast: first, at a single-participant level, we estimated the contrasted activation maps for all the rTMS conditions (i.e., excitatory, inhibitory, and sham conditions); we then estimated a group-level activation map and confirmed activation of the fronto basal ganglia network during response inhibition; and, finally, based on this map, we defined the coordinates of five ROIs (Fig. 1C; Table 1).

The ROIs were defined as a sphere with a $4 \mathrm{~mm}$ radius. Regarding STN, previous anatomical studies suggest a smaller or larger ROI volume: 2.5 $\mathrm{mm}$ radius was adopted by Coxon et al., 2012, whereas a $5 \mathrm{~mm}$ radius was by Forstmann et al., 2012. Although we examined both cases, the main analysis used a 4-mm-radius sphere as an ROI definition for STN to control detectability between different ROIs.

ROI analysis and whole-brain analysis. Using these ROIs, we calculated six types of brain activity for each participant: (pre-rTMS/post-rTMS) $\times$ (excitatory/inhibitory/sham rTMS condition). For excitatory and inhibitory rTMS conditions, we first performed a repeated-measures two-way ANOVA of brain activity [(pre-rTMS/post-rTMS $) \times($ real rTMS/sham $)]$ and assessed rTMS effects as an interaction of the ANOVA. We then directly evaluated the rTMS effects with post hoc $t$ tests.

In group-level whole-brain analysis, we performed $t$ tests using the successful stop - failed stop contrast images. Technically, increases induced by excitatory rTMS were calculated as [(successful - failed stop $\left.)_{\text {post-rTMS }}-(\text { successful }- \text { failed stop })_{\text {pre-rTMS }}\right]_{\text {excitatory rTMS }}-[$ (successful - failed stop $\left.)_{\text {post-rTMS }}-(\text { successful - failed stop })_{\text {pre-rTMS }}\right]_{\text {sham }}$, whereas decreases induced by inhibitory rTMS were quantified as [(successful - failed stop $\left.)_{\text {post-rTMS }}-(\text { successful }- \text { failed stop })_{\text {pre-rTMS }}\right]_{\text {sham }}-[($ successful - failed stop) $\left.)_{\text {post-rTMS }}-(\text { successful }- \text { failed stop })_{\text {pre-rTMS }}\right]_{\text {inhibitory rTMS }}$.

fMRI scanning and analysis for resting state. Images for rsfMRI analysis were recorded in two runs with $5 \mathrm{~min}$ of rest with the same protocol as the functional images obtained during SST. The first five images of each run were discarded to minimize transient magnetic saturation effects.

The rsfMRI images underwent preprocessing consisting of realignment, slice-timing correction, and normalization to the default template with interpolation to a $2 \times 2 \times 2 \mathrm{~mm}^{3}$ space using SPM8 software. We then performed temporal bandpass filtering $(0.01-0.1 \mathrm{~Hz})$ with in-house MATLAB scripts and conducted spatial smoothing (FWHM, $8 \mathrm{~mm}$, Gaussian filter) using SPM8 software. The images were corrected for participants' head motion and the run effect. Considering recent debates on simple regression out of whole-brain signals (Van Dijk et al., 2010; Hayasaka, 2013), we corrected such global signals though a principle component analysis (Chai et al., 2012) using CompCor (Behzadi et al., 2007) in the CONN toolbox (Whitfield-Gabrieli and Nieto-Castanon, 2012).

We then extracted time series of rsfMRI signals from the five ROIs and estimated resting-state functional connectivity (rsFC) by calculating Pearson's correlation coefficients between the time series. Because the current fronto basal ganglia network comprised the five ROIs and had 10 potential rsFC values, we calculated correlation coefficients of all these rsFC values and then transformed the coefficients into $z$-values with Fisher's transformation. The effects of rTMS were quantified using these $z$-values. 


\begin{tabular}{|c|c|c|c|c|c|c|}
\hline & \multicolumn{2}{|l|}{ Excitatory rTMS } & \multicolumn{2}{|l|}{ Inhibitory rTMS } & \multicolumn{2}{|l|}{ Sham } \\
\hline & Pre & Post & Pre & Post & Pre & Post \\
\hline SSRT (ms) & $204.8 \pm 17.4$ & $177.1 \pm 21.4$ & $175.1 \pm 22.4$ & $195.3 \pm 21.7$ & $191.4 \pm 19.2$ & $187.2 \pm 23.1$ \\
\hline $\mathrm{SSD}(\mathrm{ms})$ & $334.5 \pm 45.5$ & $359.6 \pm 32.3$ & $382.8 \pm 30.1$ & $333.4 \pm 36.8$ & $350.4 \pm 32.9$ & $350.5 \pm 39.3$ \\
\hline Response time (ms) & $539.5 \pm 39.5$ & $547.5 \pm 34.0$ & $560.0 \pm 26.1$ & $512.0 \pm 27.2$ & $545.8 \pm 30.8$ & $541.5 \pm 38.2$ \\
\hline Correct response to Go signal (\%) & $95.2 \pm 1.3$ & $91.6 \pm 6.1$ & $97.5 \pm 0.6$ & $97.3 \pm 1.2$ & $96.6 \pm 1.8$ & $95.9 \pm 1.5$ \\
\hline Correct response to Stop signal (\%) & $55.6 \pm 3.0$ & $52.7 \pm 1.5$ & $52.8 \pm 1.1$ & $52.8 \pm 0.6$ & $52.8 \pm 1.0$ & $53.1 \pm 1.0$ \\
\hline
\end{tabular}

Data are reported as the mean \pm SEM.

We also performed whole-brain analysis of rsFC with pre-SMA: using the preprocessed whole-brain resting-state images, we first calculated single participant-level rsFC maps by setting pre-SMA as a seed for each rTMS condition; we then estimated the group-level difference in rsFC with pre-SMA between the real rTMS conditions and the sham condition.

Finally, we examined partial correlations among pre-SMA, STR, and STN to more closely specify rTMS-induced changes in functional interactions. The partial correlation between regions $\mathrm{A}$ and $\mathrm{B}$ controlled by region $\mathrm{C}$ was calculated as follows:

$$
\left(r_{\mathrm{AB}}-r_{\mathrm{AC}} r_{\mathrm{BC}}\right) / \sqrt{1-r_{\mathrm{AC}}^{2}} \sqrt{1-r_{\mathrm{BC}}^{2}}
$$

where $r_{\mathrm{AB}}$ represents the rsFC between regions $\mathrm{A}$ and $\mathrm{B}$.

Confirmatory analysis using anatomical ROIs. For confirmatory analysis, we repeated all the ROI analyses using anatomically defined ROIs (see Fig. 5A). Different from the functional ROIs, these newly defined anatomical ROIs are independent of the current fMRI recording and are free from concerns about circular analysis. This analysis was also expected to ease another concern due to the difference between the fMRI contrast used in defining the functional ROIs (i.e., successful stop - go) and one used in the main ROI analysis above (i.e., successful stop - failed stop).

The MNI coordinates of pre-SMA ana and $\mathrm{STR}_{\text {ana }}$ (ana: anatomical ROI) were defined as $[6,6,62]$ and $[16,2,10]$, respectively, based on our previous study (Chikazoe et al., 2009). The center of rtIFC $_{\text {ana }}$ was set at coordinates $[48,16,18]$ according to a previous study (Levy and Wagner, 2011). The coordinates of $\mathrm{STN}_{\text {ana }}$ and $\mathrm{GPi}_{\text {ana }}$ were defined as $[10,-12$, $-8]$ and $[14,6,0]$, respectively, based on a previous anatomical study (Forstmann et al., 2012) and a meta-analysis (Swick et al., 2011). These ROIs were spheres with a $4 \mathrm{~mm}$ radius.

\section{Results}

\section{Behavior}

The participants accurately responded to go signals with $\sim 50 \%$ correct responses to stop signals (Table 2), which is comparable to previous reports (Aron and Poldrack, 2006; Li et al., 2006) and had no significant difference between rTMS conditions $(p>$ 0.16 , paired $t$ tests, between the real rTMS conditions and sham condition). Significant differences across pre/post sessions or across rTMS conditions were not observed in RT, mean SSD, or mean trial length (RT, $p>0.09$; mean SSD, $p>0.10$; mean trail length, $p>0.12$; paired $t$ tests).

The current experiment could reproduce previous behavioral reports in which excitatory/inhibitory stimulation on pre-SMA decreased/increased SSRT, respectively (Chen et al., 2009; Hsu et al., 2011; Cai et al., 2012; Obeso et al., 2013; Fig. 1D). Compared with the sham condition, SSRT significantly decreased after the excitatory rTMS $\left(p=0.05, t_{(8)}=1.8\right.$, one-tailed paired $t$ test $)$ and significantly increased after the inhibitory rTMS $\left(p=0.04, t_{(8)}=\right.$ 2.0 , one-tailed paired $t$ test). SSRT in pre-rTMS sessions showed no significant differences between the real rTMS and sham conditions $(p>0.09)$, which suggests that the pre-rTMS baseline of SSRT was comparable between different conditions.

\section{ROI analysis}

Using functionally defined ROIs (Fig. 1C; Table 1), we first examined the effects of rTMS on brain activity defined by a successful stop-go contrast (Fig. 2A), but could not find significant effects except in pre-SMA activity (excitatory, $p=0.02$; inhibitory, $p=0.04$; post hoc paired $t$ tests). As discussed later, the results might be due to the current task design with no-choice go trials and fixed intertrial intervals (ITIs).

We therefore calculated the neural effects of rTMS with a successful stop-failed stop contrast and found significant modulations in three of the five ROIs (Fig. 2B). First, pre-SMA activity was significantly modulated. Compared with the sham condition, the activity increased after the excitatory rTMS $[p=0.01$, $F_{(1,32)}=6.7$, an interaction in a repeated-measures two-way ANOVA, (pre-rTMS/post-rTMS) $\times($ rTMS/sham $) ; p=0.0001$, $t_{(8)}=4.6$, post hoc paired $t$ test between (post - pre) $)_{\text {rTMS }}$ and (post - pre $\left.)_{\text {sham }}\right]$ and decreased after the inhibitory rTMS $(p=$ $0.004, F_{(1,32)}=9.5$, ANOVA; $p=0.0001, t_{(8)}=6.4$, post hoc paired $t$ test).

In STR and GPi, qualitatively similar changes were observed. STR activity increased after the excitatory rTMS ( $p=$ $0.01, F_{(1,32)}=7.1$, ANOVA; $p=0.001, t_{(8)}=4.5$, post hoc paired $t$ test $)$ and decreased after the inhibitory rTMS $(p=0.04$, $F_{(1,32)}=4.7$, ANOVA; $p=0.04, t_{(8)}=2.0$, post hoc paired $t$ test); in GPi, the excitatory rTMS increased the activity $(p=0.009$, $F_{(1,32)}=7.9$, ANOVA; $p=0.00006, t_{(8)}=6.9$, post hoc paired $t$ test $)$, and the inhibitory rTMS decreased it $\left(p=0.01, F_{(1,32)}=\right.$ 7.3 , ANOVA; $p=0.01, t_{(8)}=2.9$, post hoc paired $t$ test).

In rtIFC and STN, we could not detect significant effects of either type of rTMS (rtIFC: $p>0.4$, ANOVA; $p>0.3$, paired $t$ tests; STN: $p>0.6$, ANOVA; $p>0.6$, paired $t$ tests).

\section{Whole-brain analysis}

To confirm the spatial specificity of these rTMS effects seen in the ROI analysis, we performed whole-brain analyses. After correction for multiple comparisons ( $p<0.05$, corrected by familywise error rate), no significant neural effects of rTMS were detected; however, under a moderate statistical threshold $\left(P_{\text {uncorrected }}<\right.$ $0.005 ; \geq 10$ voxels; Table 3 ), we found significant activity changes that were consistent with the results of the ROI analysis: activity of brain areas close to the predefined pre-SMA, STR, and GPi increased after the excitatory rTMS (Fig. 2C) and decreased after the inhibitory rTMS (Fig. 2D). Areas near rtIFC and STN did not show such rTMS-induced activity modulations.

\section{Correlation between behavior and activity change}

These activity modulations in pre-SMA, STR, and GPi were significantly correlated with the rTMS-induced behavioral changes (Fig. 3). In the excitatory rTMS condition, the activity changes of the three ROIs were negatively correlated with the effects on SSRT (pre-SMA: $r=-0.70, p=0.04$; STR: $r=-0.69, p=0.04$; 
A

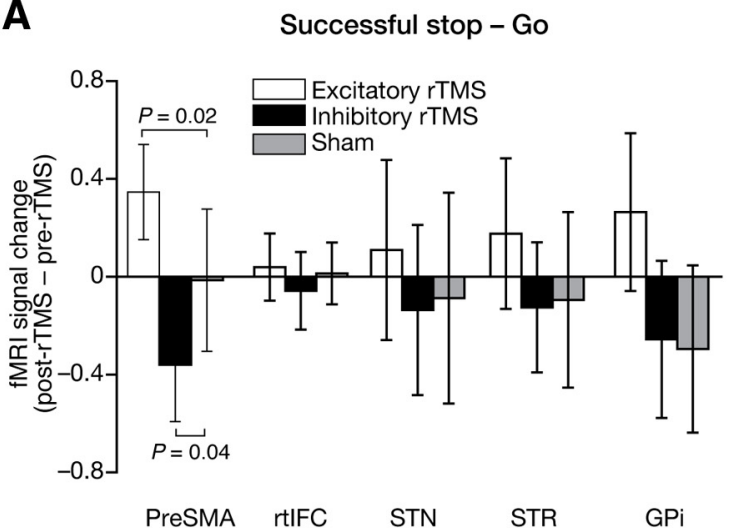

B Successful stop - Failed stop

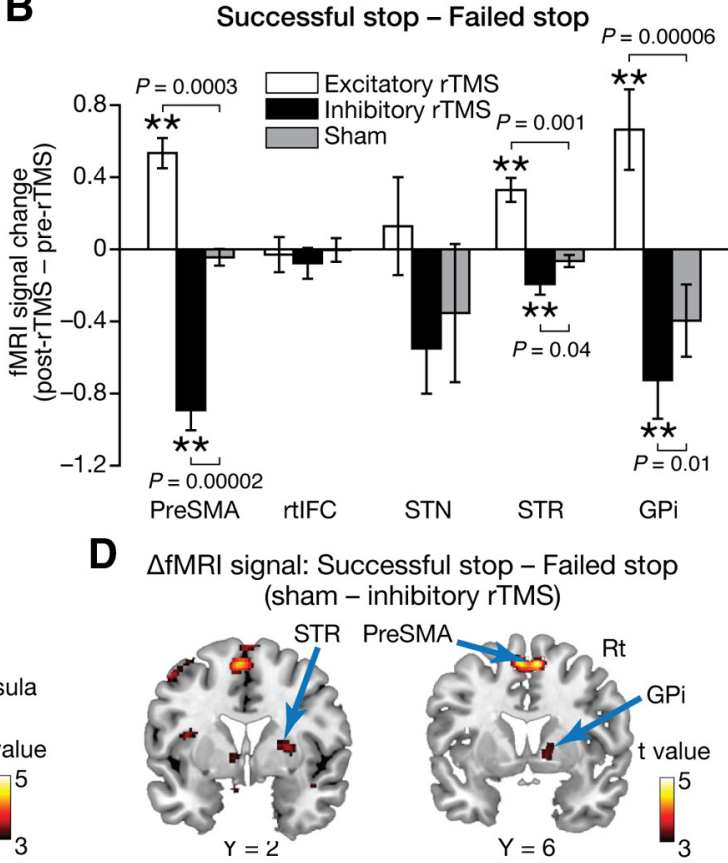

Figure 2. ROl analysis. A, rTMS effects on [successful stop - go] activity. They-axis represents the activity calculated as [(successful stop - go $\left.)_{\text {post-rTMs }}-(\text { successful stop }- \text { go })_{\text {pre-rTMs }}\right]_{\text {excitatory/inhibitory }}-$ [(successful stop - go $\left.)_{\text {post-rTMs }}-(\text { successful stop }- \text { go })_{\text {pre-rTMs }}\right]_{\text {sham }}$. We observed significant rTMS effects only in pre-SMA. The error bars indicate the SEM. $\boldsymbol{B}$, rTMS effects on [successful stop - failed stop] activity. The $y$-axis represents $\left[(\text { successful }- \text { failed stop })_{\text {post-rTMs }}-(\text { successful }- \text { failed stop })_{\text {pre-rMs }}\right]_{\text {excitatory/inhibitory }}-\left[(\text { successful }- \text { failed stop })_{\text {post-rTMs }}-(\text { successful }- \text { failed stop })_{\text {pre-rTMs }}\right]_{\text {sham }}$ activity. Significant rTMS effects were observed in pre-SMA, STR, and GPi. ${ }^{* *} p<0.01$, one-sample $t$ test. C, Effects of the excitatory rTMS. The statistical parametric map shows the results of group-level analysis of rTMS-induced increases in brain activity that were defined as [(successful - failed stop) $\left.)_{\text {post-rTMS }}-(\text { successful }- \text { failed stop) })_{\text {pre-rTMs }}\right]_{\text {excitatory rTMs }}-[$ (successful - failed stop) post-rTMs $-($ successful - failed stop) pre-rTMs $_{\text {sham }} \cdot \boldsymbol{D}$, Effects of the inhibitory rTMS. The statistical parametric map shows the results of a group-level analysis of rTMS-induced decreases in brain activity that was defined as [(successful - failed stop $\left.)_{\text {post-rTMs }}-(\text { successful }- \text { failed stop })_{\text {pre-rTMs }}\right]_{\text {sham }}-\left[(\text { successful }- \text { failed stop })_{\text {post-rTMs }}-(\text { successful }- \text { failed stop })_{\text {pre-rms }}\right]_{\text {inhibitory rtms. }}$ Rt, Right.

Table 3. Results of whole-brain analysis

\begin{tabular}{|c|c|c|c|c|c|}
\hline \multirow[b]{2}{*}{ Anatomical label } & \multirow[b]{2}{*}{ Hemisphere } & \multicolumn{3}{|c|}{ MNI coordinates } & \multirow[b]{2}{*}{$t$ value } \\
\hline & & $x$ & $y$ & $z$ & \\
\hline \multicolumn{6}{|l|}{ Excitatory rTMS-sham } \\
\hline Pre-SMA & Left & -8 & 10 & 44 & 4.9 \\
\hline Insula & Right & 38 & 18 & -12 & 4.9 \\
\hline Pre-SMA & Right & 4 & 8 & 42 & 4.2 \\
\hline GPi & Right & 16 & 4 & 2 & 3.8 \\
\hline STR & Right & 26 & 2 & 6 & 3.6 \\
\hline \multicolumn{6}{|l|}{ Sham-inhibitory rTMS } \\
\hline Pre-SMA & Left & -4 & 2 & 56 & 4.8 \\
\hline Pre-SMA & Right & 8 & 12 & 56 & 4.7 \\
\hline Inferior occipital lobule & Left & -44 & -72 & -8 & 4.6 \\
\hline Precuneus & Left & -12 & -68 & 54 & 3.9 \\
\hline STR & Right & 24 & -2 & 8 & 3.6 \\
\hline GPi & Right & 14 & 6 & -2 & 3.5 \\
\hline
\end{tabular}

GPi: $r=-0.71, p=0.03$; Fig. $3 A$ ). In the inhibitory rTMS condition, qualitatively the same associations were observed (preSMA: $r=-0.71, p=0.03$; STR: $r=-0.69, p=0.04$; GPi: $r=-0.71, p=0.03$; Fig. $4 B$ ). In contrast, no significant correlation was seen in rtIFC and STN (rtIFC, $p>0.3$; STN, $p>0.7$ ). These activity-behavior associations imply that increases in brain activity in pre-SMA, STR, and GPi would improve behavioral capability for response inhibition.

\section{Effects on rsFC}

We also evaluated rTMS effects on intrinsic functional interactions among these five ROIs. Of the 10 rsFCs constituting the fronto basal ganglia network, only three rsFCs showed significant changes after rTMS (pre-SMA-STR, STR-GPi, and GPi-pre-
SMA connectivity; Fig. $4 A$ ). The magnitudes of the three rsFCs increased after the excitatory rTMS and decreased after the inhibitory rTMS (excitatory/inhibitory: pre-SMA-STR, $p=0.007 /$ $0.007, t_{(8)}=3.1 / 3.1$; STR-GPi, $p=0.006 / 0.03, t_{(8)}=3.3 / 2.3$; GPi-pre-SMA, $p=0.02 / 0.03, t_{(8)}=2.4 / 2.3$; paired $t$ tests). The changes observed in the three rsFCs were also significantly different between the excitatory and inhibitory rTMS conditions (preSMA-STR: $p=0.0006, t_{(8)}=4.8$; STR-GPi: $p=0.006, t_{(8)}=3.1$; GPi-pre-SMA: $\left.p=0.006, t_{(8)}=3.2\right)$.

Two other rsFCs (pre-SMA-rtIFC and pre-SMA-STN) showed significant differences only between the excitatory and inhibitory rTMS conditions ( $p<0.03$, paired $t$ tests; Fig. $4 A$ ), but the other rsFCs were not significantly affected by the rTMS (Fig. $4 B$ ). The spatial specificity of these results was partially confirmed by a whole-brain analysis of rsFC with pre-SMA as a seed (Fig. $4 C)$. In both of the rTMS conditions, we found moderate rsFC changes around STR and GPi $\left(P_{\text {uncorrected }}<0.005, \geq 10\right.$ voxels $)$.

\section{Effects on partial correlations}

Furthermore, we more precisely quantified the rTMS effects on functional interactions between the three highly interacted ROIs (i.e., pre-SMA, STR, and GPi) by calculating partial correlations between them; in fact, when brain regions are mutually connected, calculations based on Pearson's correlation coefficients might detect spurious functional connections. Consequently, significant effects were found only in pre-SMA-STR and STR-GPi interactions (excitatory/inhibitory: pre-SMA-STR, $p=0.02 / 0.04, t_{(8)}=$ 2.3/2.0; STR-GPi, $p=0.04 / 0.04, t_{(8)}=2.1 / 2.0$; paired $t$ tests; Fig. $4 D)$. The magnitudes of these connectivity changes were significantly correlated with the SSRT changes (excitatory/inhibitory: pre-SMA-STR, $r=-0.73 /-0.69, p=0.02 / 0.04$; STR-GPi, $r=$ 


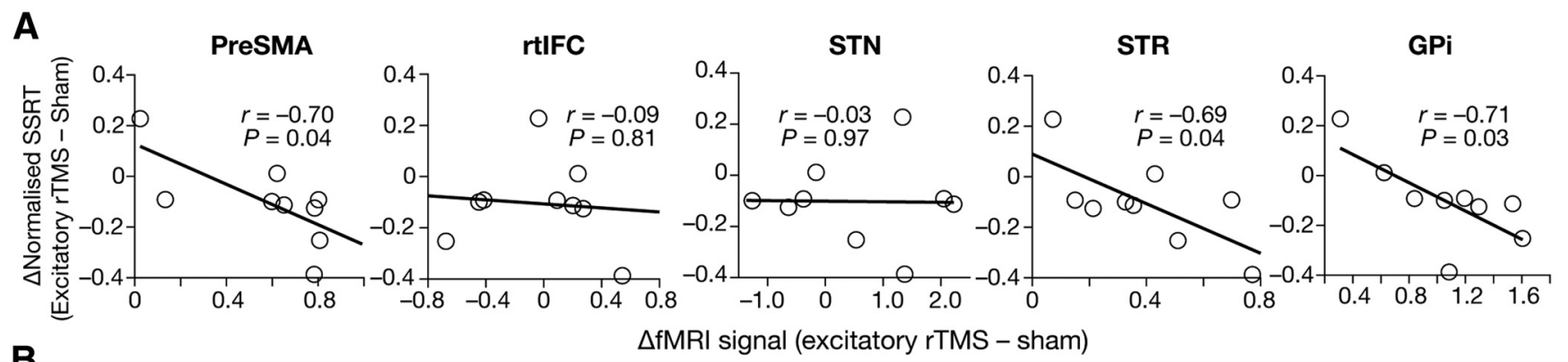

B

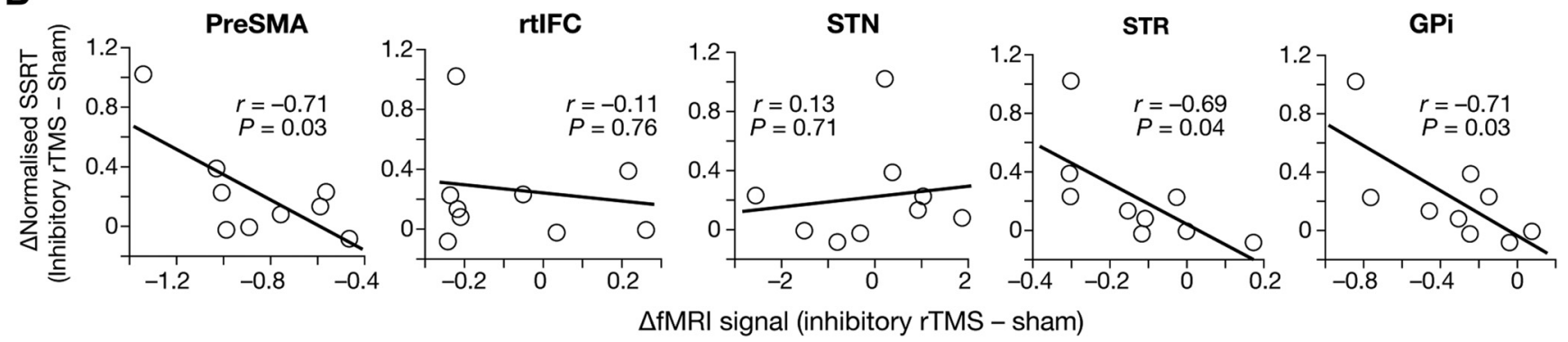

Figure 3. Correlations between brain activity and behavior. $\boldsymbol{A}$, Excitatory rTMS. The $x$-axes show brain activity changes, which were calculated as [(successful - failed stop) $)_{\text {post-rTMs }}-$ $\left.(\text { successful }- \text { failed stop })_{\text {pre-rTMs }}\right]_{\text {excitatory rTMs }}-\left[(\text { successful }- \text { failed stop })_{\text {post-rTMs }}-(\text { successful }- \text { failed stop })_{\text {pre-rTMs }}\right]_{\text {sham }}$. The $y$-axes show SSRT changes. Each dot represents a record of each participant. $\boldsymbol{B}$, Inhibitory rTMS. The $x$-axes show brain activity changes of ROls, which were calculated as [(successful - failed stop) $\left.)_{\text {post-rTMs }}-(\text { successful }- \text { failed stop })_{\text {pre-rTMs }}\right]_{\text {sham }}-$

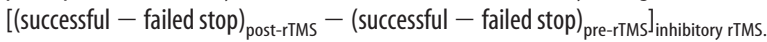

$-0.76 /-0.73, p=0.01 / 0.02$; Fig. $4 E, F)$. In contrast, no significant correlation with behavioral changes was seen in pre-SMAGPi connectivity $(p>0.27)$.

\section{Confirmatory analysis}

Finally, we examined these neural effects of rTMS by adopting new anatomically defined ROIs (Fig. 5A) and successfully observed qualitatively the same effects (Fig. $5 B-H$ ).

First, significant rTMS effects on brain activity were seen only in pre-SMA ${ }_{\text {ana }}, \mathrm{STR}_{\mathrm{ana}}$, and $\mathrm{GPi}_{\text {ana }}$ in both of the excitatory and inhibitory conditions $(p<0.001$, paired $t$ tests; Fig. $5 B)$. The activity changes in the three ROIs showed significantly negative correlations with the SSRT changes (excitatory rTMS condition: $r<-0.69$; $p<0.04$; Fig. 5C; inhibitory rTMS condition: $r<$ $-0.65 ; p \leq 0.05$; Fig. $5 D$ ). Moreover, compared with the sham condition, the rTMS induced significant changes in rsFC only between pre-SMA ana $\mathrm{STR}_{\mathrm{ana}}$, and $\mathrm{GPi}_{\text {ana }}(p<0.05$; Fig. $5 E)$. In particular, the partial correlation analysis showed that the critical changes in functional interactions were induced in pre-SMA ${ }_{\mathrm{ana}}-$ $\mathrm{STR}_{\text {ana }}$ and $\mathrm{STR}_{\mathrm{ana}}-\mathrm{GPi}_{\text {ana }}$ pathways (Fig. $5 F$ ). These partial correlation changes were, furthermore, predictive of the rTMSinduced SSRT modulations in both the excitatory $(p<0.05$; Fig. $5 G$ ) and inhibitory ( $p \leq 0.05$; Fig. $5 H$ ) rTMS conditions. These results were qualitatively unchanged even when we adopted different ROI sizes for STN.

\section{Discussion}

Using quadripulse rTMS, we examined causal effects of pre-SMA activity on the fronto basal ganglia network during response inhibition. STR and GPi activity were affected by the stimulation of pre-SMA activity, and the activity changes were correlated with modulations of the behavioral performance of response inhibition. Moreover, pre-SMA-STR and STR-GPi functional interactions were also modulated by rTMS of pre-SMA, and their magnitudes were predictive of the behavioral influence. In contrast, such causal effects were not observed in the activity and functional interactions involving rtIFC and STN. These results suggest that rTMS of pre-SMA can behaviorally change response inhibition through modulating the activity of the pre-SMASTR-GPi pathway, and provide evidence for the top-down regulation from pre-SMA to GPi via STR during successful response inhibition.

The current behavioral observations are consistent with those made in previous studies (Chen et al., 2009; Hsu et al., 2011; Cai et al., 2012; Obeso et al., 2013). Regardless of the difference in stimulation methods, these studies commonly reported that the disruption of pre-SMA activity behaviorally impaired response inhibition. Regarding SSRT, one study (Hsu et al., 2011) has demonstrated that anodal transcranial direct current stimulation can shorten the SSRT, and the current study is, to the best of our knowledge, the first report showing a similar effect using rTMS. These previous and present findings support the insight that preSMA has a critical role in response inhibition.

The fronto basal ganglia network for response inhibition mainly consists of the following three pathways: cortex-STNGPi pathway (hyperdirect pathway), cortex-STR-GPi (direct pathway), and cortex-STR-globus pallidus pars externa (GPe)GPi pathway (indirect pathway; Nambu et al., 2002; Aron and Poldrack, 2006; Chambers et al., 2009; Hikosaka and Isoda, 2010; Aron et al., 2014). The current findings suggest that rTMS of pre-SMA mainly affects the indirect pathway. First, the current coactivation/deactivation of STR and GPi after stimulation of pre-SMA seems to contradict the direct pathway model in which STR inhibits GPi activity (Hikosaka and Isoda, 2010). In contrast, the indirect pathway appears to be fitted to the current results. In the pathway, successful response inhibition is achieved by excitatory interaction from cortical areas to STR, and inhibitory effects from STR to GPe and GPe to GPi (Nambu et al., 2002; Aron et al., 2014); therefore, brain activity in cortical regions, STR, and GPi should be modulated in the same direction, which is consistent with the current findings (Fig. $2 B-D$ ).

If this interpretation is valid, the hyperdirect pathway and indirect pathway could work independently. In fact, such an as- 
A
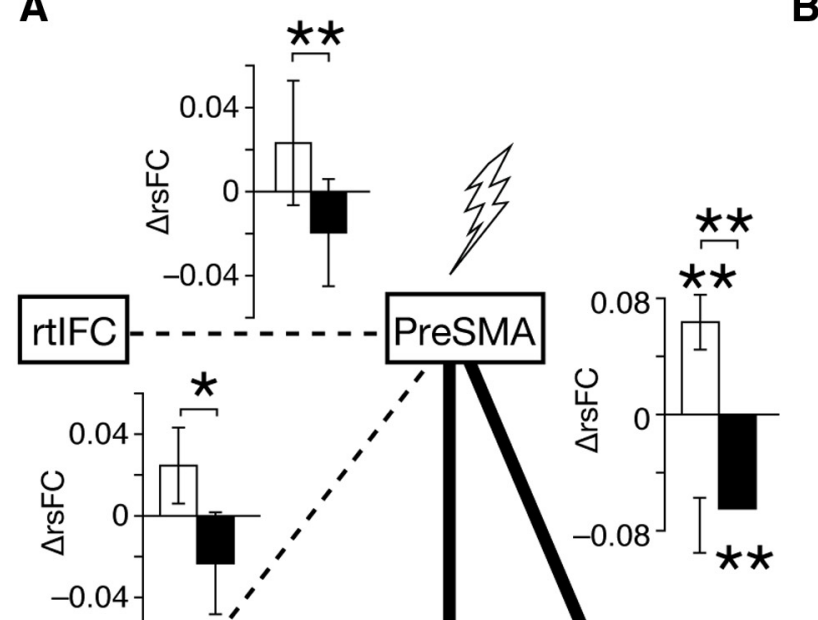

$-0.04$

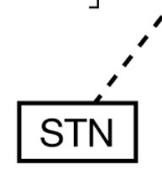

0

D

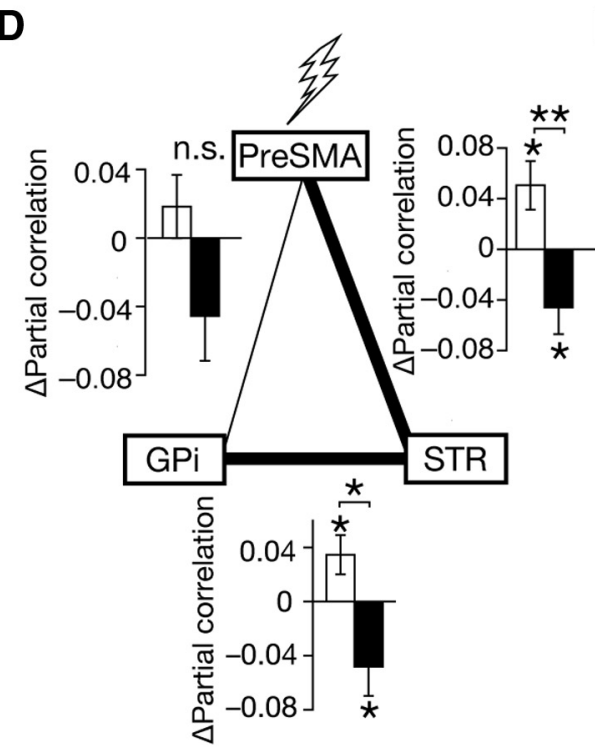

Excitatory rTMS - Sham Inhibitory rTMS - Sham
B
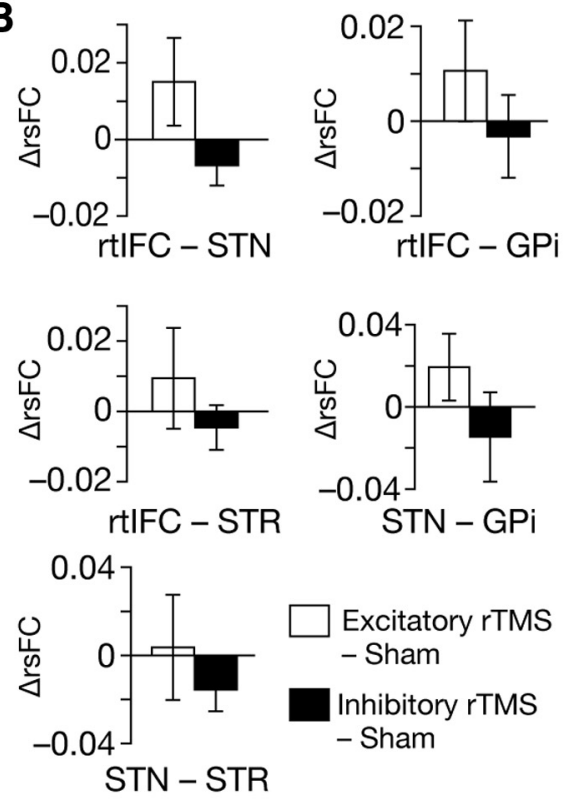

C

$\triangle \mathrm{rsFC}$ with PreSMA

$\begin{array}{ll}\text { Excitatory } & \text { Sham } \\ \text { - sham } & \text { - inhibitory }\end{array}$

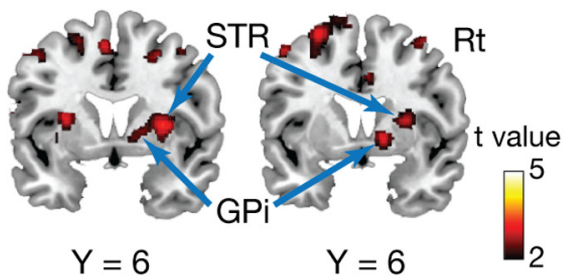

E

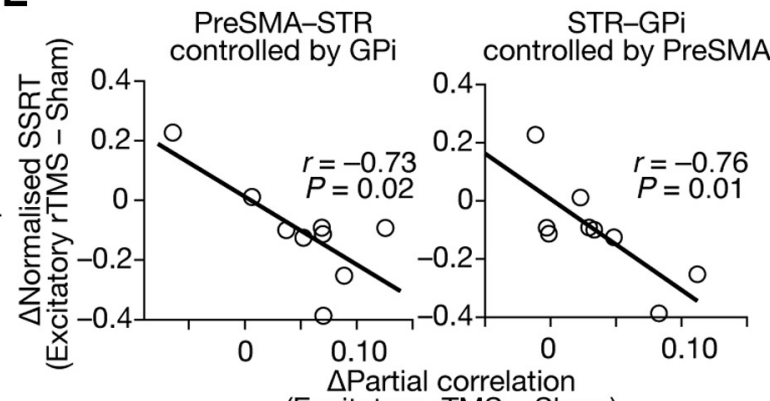

F

(Excitatory rTMS - Sham)

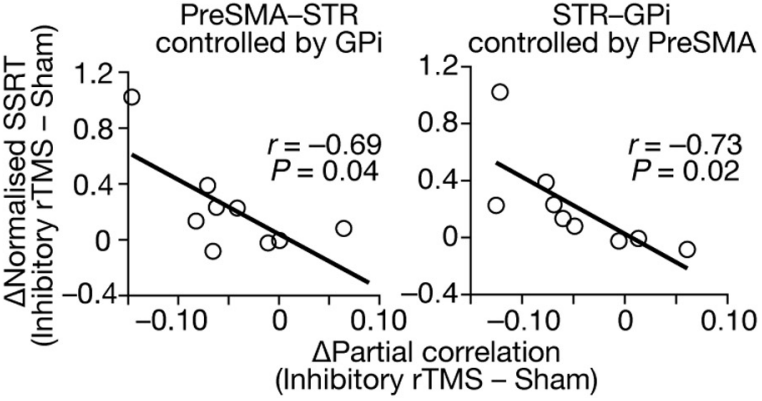

Figure 4. Effects on rsFC. $A, B$, rTMS effects on rsFC in the fronto basal ganglia network. Significant changes were found only in rsFC between pre-SMA, STR, and GPi. rsFCs between pre-SMA and rtIFC, and between pre-SMA and STN did not show such effects, but had significantly different values between the two types of rTMS condition. The error bars indicate the SEM. ${ }^{*} p<0.05,{ }^{* *} p<$ 0.01 , paired $t$ tests. C, Whole-brain rsFC analysis. The statistical parametric maps show the difference in rsFC with pre-SMA as a seed between the real rTMS and sham conditions. The maps show the spatial specificity of the rsFC changes detected in the ROl analysis. $\boldsymbol{D}-\boldsymbol{F}$, Partial correlation among pre-SMA, STR, and GPi. In partial correlation analysis, significant rTMS effects were observed only in interactions between pre-SMA and STR, and between STR and GPi. Partial correlation changes in both region pairs were significantly correlated with SSRT changes. ${ }^{*} p<0.05,{ }^{* *} p<0.01$, paired $t$ tests. 
A

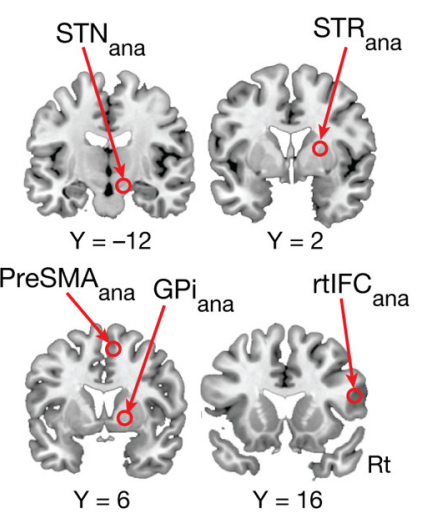

B

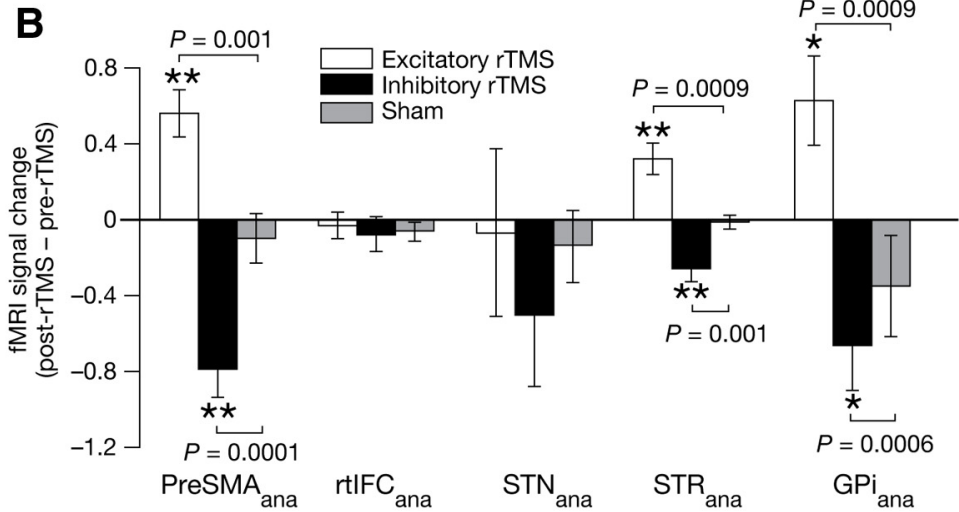

C

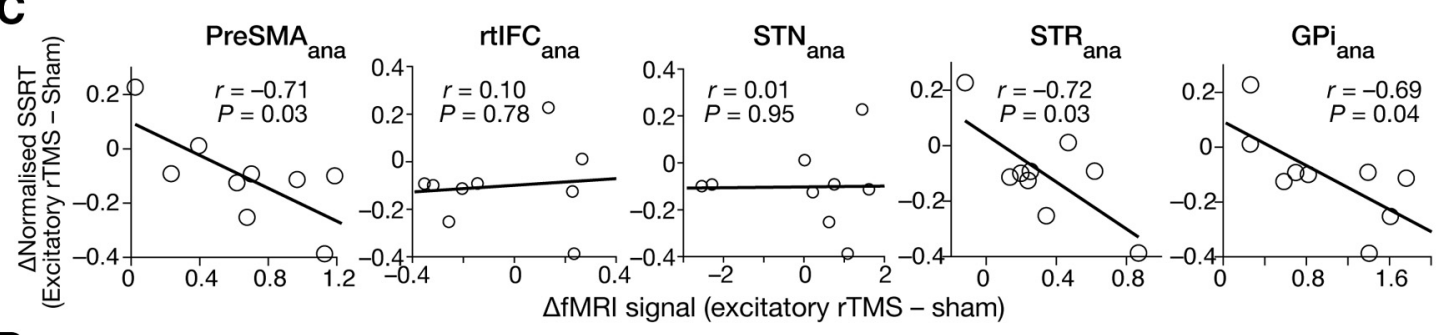

D
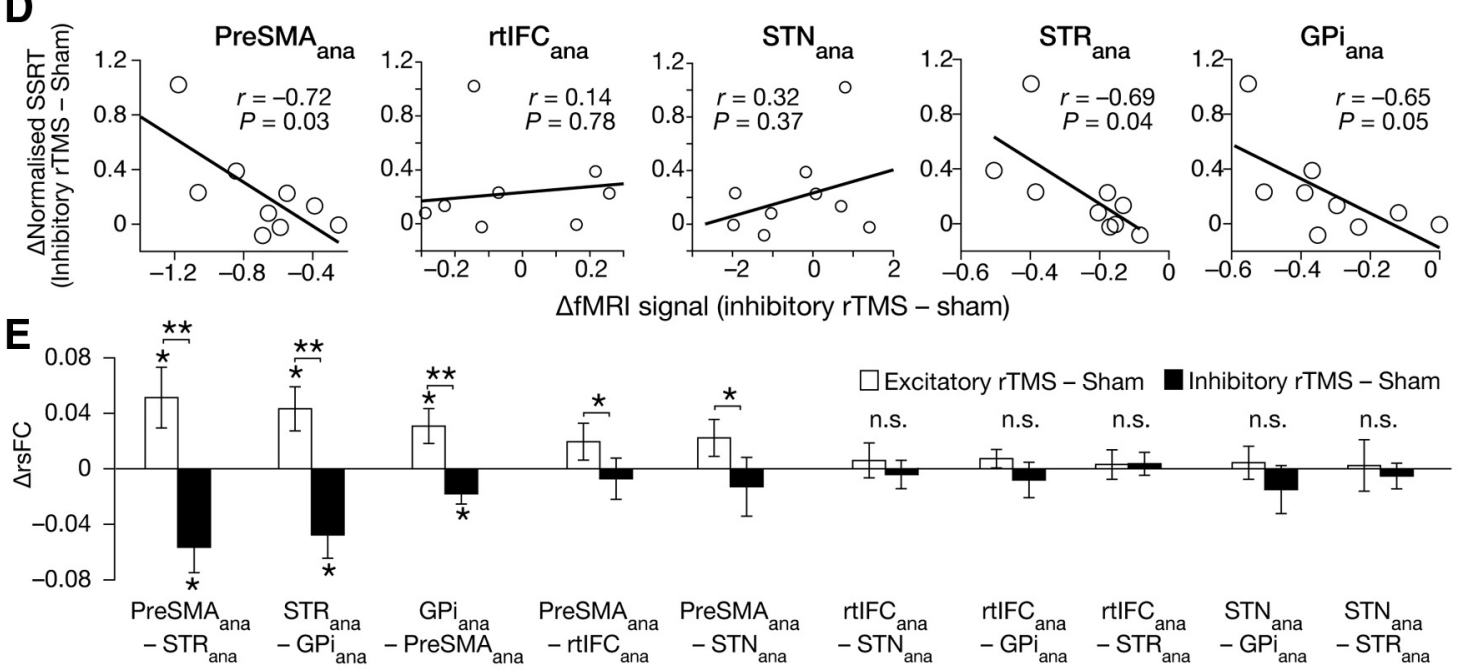

F $\square$ Excitatory rTMS - Sham

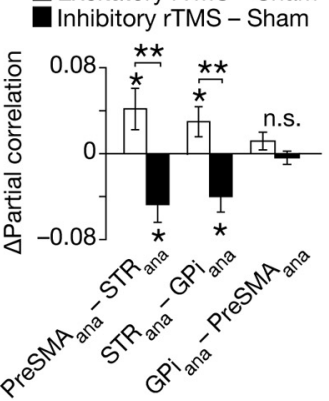

G

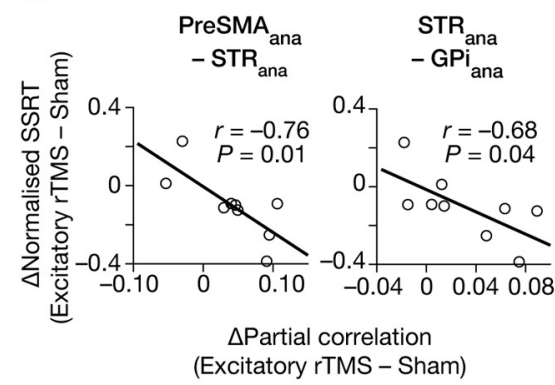

H

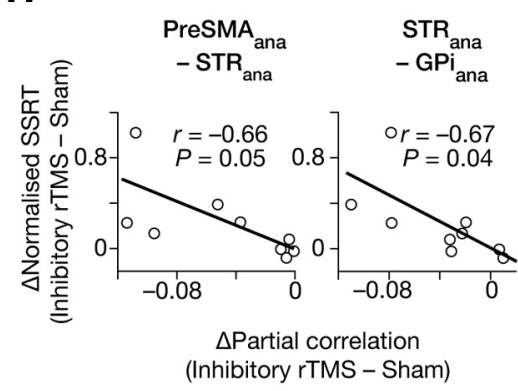

Figure 5. Confirmatory analysis using anatomical ROIs. $A$, Anatomical ROIs. The MNI coordinates of the ROls were based on previous studies. pre-SMA ${ }_{\text {anar }}[6,6,62] ; S_{\text {STR }}{ }_{\text {ana }}[16,2,10](C h i k a z o e$ et al., 2009). rtIFC $\mathrm{ana}_{\text {r }}[48,16,18]$ (Levy and Wagner, 2011). STN $_{\text {ana }}[10,-12,-8]$ (Forstmann et al., 2012). GPi ${ }_{\text {ana }}[14,6,0]$ (Swick et al., 2011). $\boldsymbol{B}$, Effects on brain activity. The brain activity change $\left.(y \text {-axis) was defined as [(successful - failed stop })_{\text {post-rTMs }}-(\text { successful }- \text { failed stop })_{\text {pre-rTMs }}\right]_{\text {excitatory/inhibitory }}-\left[(\text { successful }- \text { failed stop })_{\text {post-rTMs }}-(\text { successful }- \text { failed stop })_{\text {pre-rTMs }}\right]_{\text {sham }}$. ${ }^{*} p<0.05,{ }^{* *} p<0.01$, posthoc paired $t$ tests. C, Correlations with behavior: excitatory rTMS. The $x$-axes are calculated as stated in Figure $3 A$.D. Correlation with behavior: inhibitory rTMS. The $x$-axes

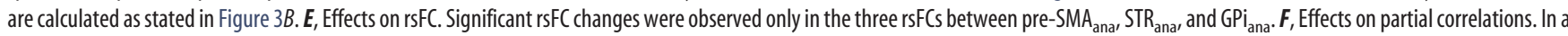

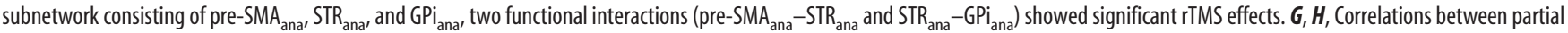
correlation changes and behavioral effects. Increases in functional interaction seem to support the behavioral improvement of response inhibition. 
sumption of independence can explain the current negative results seen in rtIFC and STN activity. In an intact condition, the two pathways work with some coordination (Neubert et al., 2010; Swann et al., 2012); however, once an intervention is made in one of the pathways, the remaining pathway might begin to work independently.

The current study also adds new observations about the effects of rTMS on rsFC. Since an early study by Grefkes et al. (2010), a series of human neuroimaging studies have investigated the influence of rTMS on resting-state brain activity (Fox et al., 2012, 2013): low-frequency inhibitory rTMS of left dorsolateral prefrontal cortex (DLPFC) reduced the activity of default mode network (DMN; van der Werf et al., 2010); excitatory rTMS of inferior parietal lobule generally decreased rsFC in DMN, whereas inhibitory rTMS increased rsFC in DMN (Eldaief et al., 2011); and similar effects of excitatory and inhibitory rTMS on rsFC between bilateral primary motor areas were also observed (Watanabe et al., 2014). In contrast, other studies reported that no significant effect of $5 \mathrm{~Hz}$ rTMS of DLFPC was found in rsFC between the DLPFC and hippocampus (Bilek et al., 2013), and that the effects of their excitatory theta-burst rTMS were limited to relatively narrow brain areas (Nettekoven et al., 2014). At a glance, these reports appear to contain some inconsistency, but they might simply suggest that rTMS-induced changes in rsFC vary between different sets of brain regions and brain networks. In fact, the current rTMS effects on rsFC also highly dependent on region pairs (Fig. $4 A-C$ ). In the 10 rsFCs between the five ROIs, only 3 rsFCs showed significant rTMS effects; moreover, the directions of the effects on 1 rsFC (i.e., between STN and STR) were the opposite of those seen in the other rsFCs. It might be necessary to assume that rTMS effects on rsFC between a specific region pair cannot be directly applied to those between other region pairs.

One of the limitations of the current study is in the relatively small number of participants. It is difficult to deny the causal effects of pre-SMA on rtIFC or STN during response inhibition. In fact, the two regions are anatomically connected with each other and can have somewhat causal relationships during SST (Aron et al., 2007). In addition, although its finding is based on the observations of a single patient, a previous study (Swann et al., 2012) reported an increase in rtIFC activity after microstimulation of pre-SMA. It will be necessary not only to investigate the neural effects of the stimulation of pre-SMA with more participants, but also to examine the influences of rtIFC on pre-SMA.

Another limitation is in the current paradigm of SST. Here, we neither implemented a choice task in go trials, nor adopted jittered ITIs. As a result, the current settings might have somewhat allowed the participants to anticipate the onset timing of go trials, which would have resulted in relatively earlier initiation of go processes than in other SST experiments with choice tasks in go trials or jittered ITIs. The effects of this possibly early start of the go process on SSRT are unclear: it might have extended SSRT or have lengthened SSD but left SSRT intact. Because the current findings are based on comparison with the sham condition, the observed behavioral rTMS effects were robust against this possibility of the extension of SSRT; however, we need to be cautious in the direct comparison of the current SSRT with that seen in other studies. In addition, this early initiation of the go process might have also made it difficult for us to detect rTMS effects on brain activity in the contrast between successful stop and go trials (Fig. 2A).

In the current study, we provided empirical evidence that the causal regulation from pre-SMA to GPi via STR is essential for successful response inhibition. Furthermore, the current observations on rtIFC and STN imply that the fronto basal ganglia network underlying response inhibition might consist of multiple independent pathways.

\section{References}

Albin RL, Young AB, Penney JB (1989) The functional anatomy of basal ganglia disorders. Trends Neurosci 12:366-375. CrossRef Medline

Alegre M, Lopez-Azcarate J, Obeso I, Wilkinson L, Rodriguez-Oroz MC, Valencia M, Garcia-Garcia D, Guridi J, Artieda J, Jahanshahi M, Obeso JA (2013) The subthalamic nucleus is involved in successful inhibition in the stop-signal task: a local field potential study in Parkinson's disease. Exp Neurol 239:1-12. CrossRef Medline

Alexander GE, Crutcher MD (1990) Functional architecture of basal ganglia circuits-neural substrates of parallel processing. Trends Neurosci 13:266271. CrossRef Medline

Aron AR, Poldrack RA (2006) Cortical and subcortical contributions to stop signal response inhibition: role of the subthalamic nucleus. J Neurosci 26:2424-2433. CrossRef Medline

Aron AR, Fletcher PC, Bullmore ET, Sahakian BJ, Robbins TW (2003) Stopsignal inhibition disrupted by damage to right inferior frontal gyrus in humans. Nat Neurosci 6:115-116. CrossRef Medline

Aron AR, Behrens TE, Smith S, Frank MJ, Poldrack RA (2007) Triangulating a cognitive control network using diffusion-weighted magnetic resonance imaging (MRI) and functional MRI. J Neurosci 27:3743-3752. CrossRef Medline

Aron AR, Robbins TW, Poldrack RA (2014) Inhibition and the right inferior frontal cortex: one decade on. Trends Cogn Sci 18:177-185. CrossRef Medline

Band GPH, van der Molen MW, Logan GD (2003) Horse-race model simulations of the stop-signal procedure. Acta Psychol (Amst) 112:105-142. CrossRef

Behzadi Y, Restom K, Liau J, Liu TT (2007) A component based noise correction method (CompCor) for BOLD and perfusion based fMRI. Neuroimage 37:90-101. CrossRef Medline

Bilek E, Schäfer A, Ochs E, Esslinger C, Zangl M, Plichta MM, Braun U, Kirsch P, Schulze TG, Rietschel M, Meyer-Lindenberg A, Tost H (2013) Application of high-frequency repetitive transcranial magnetic stimulation to the DLPFC alters human prefrontal-hippocampal functional interaction. J Neurosci 33:7050-7056. CrossRef Medline

Cai W, Leung HC (2009) Cortical activity during manual response inhibition guided by color and orientation cues. Brain Res 1261:20-28. CrossRef Medline

Cai W, George JS, Verbruggen F, Chambers CD, Aron AR (2012) The role of the right presupplementary motor area in stopping action: two studies with event-related transcranial magnetic stimulation. J Neurophysiol 108: 380-389. CrossRef Medline

Cai W, Cannistraci CJ, Gore JC, Leung HC (2014) Sensorimotorindependent prefrontal activity during response inhibition. Hum Brain Mapp 35:2119-2136. CrossRef Medline

Chai XJ, Castañón AN, Ongür D, Whitfield-Gabrieli S (2012) Anticorrelations in resting state networks without global signal regression. Neuroimage 59:1420-1428. CrossRef Medline

Chambers CD, Bellgrove MA, Stokes MG, Henderson TR, Garavan H, Robertson IH, Morris AP, Mattingley JB (2006) Executive "brake failure" following deactivation of human frontal lobe. J Cogn Neurosci 18:444455. Medline

Chambers CD, Bellgrove MA, Gould IC, English T, Garavan H, McNaught E, Kamke M, Mattingley JB (2007) Dissociable mechanisms of cognitive control in prefrontal and premotor cortex. J Neurophysiol 98:3638-3647. CrossRef Medline

Chambers CD, Garavan H, Bellgrove MA (2009) Insights into the neural basis of response inhibition from cognitive and clinical neuroscience. Neurosci Biobehav Rev 33:631-646. CrossRef Medline

Chatham CH, Claus ED, Kim A, Curran T, Banich MT, Munakata Y (2012) Cognitive control reflects context monitoring, not motoric stopping, in response inhibition. PLoS One 7:e31546. CrossRef Medline

Chen CY, Muggleton NG, Tzeng OJ, Hung DL, Juan CH (2009) Control of prepotent responses by the superior medial frontal cortex. Neuroimage 44:537-545. CrossRef Medline

Chikazoe J, Jimura K, Hirose S, Yamashita K, Miyashita Y, Konishi S (2009) Preparation to inhibit a response complements response inhibition dur- 
ing performance of a stop-signal task. J Neurosci 29:15870-15877. CrossRef Medline

Congdon E, Mumford JA, Cohen JR, Galvan A, Canli T, Poldrack RA (2012) Measurement and reliability of response inhibition. Front Psychol 3:37. CrossRef Medline

Coxon JP, Van Impe A, Wenderoth N, Swinnen SP (2012) Aging and inhibitory control of action: cortico-subthalamic connection strength predicts stopping performance. J Neurosci 32:8401-8412. CrossRef Medline

Drummond GB (2009) Reporting ethical matters in the Journal of Physiology: standards and advice. J Physiol 587:713-719. CrossRef Medline

Duann JR, Ide JS, Luo X, Li CS (2009) Functional connectivity delineates distinct roles of the inferior frontal cortex and presupplementary motor area in stop signal inhibition. J Neurosci 29:10171-10179. CrossRef Medline

Duque J, Olivier E, Rushworth M (2013) Top-down inhibitory control exerted by the medial frontal cortex during action selection under conflict. J Cogn Neurosci 25:1634-1648. CrossRef Medline

Eldaief MC, Halko MA, Buckner RL, Pascual-Leone A (2011) Transcranial magnetic stimulation modulates the brain's intrinsic activity in a frequency-dependent manner. Proc Natl Acad Sci U S A 108:2122921234. CrossRef Medline

Floden D, Stuss DT (2006) Inhibitory control is slowed in patients with right superior medial frontal damage. J Cogn Neurosci 18:1843-1849. CrossRef Medline

Forstmann BU, Keuken MC, Jahfari S, Bazin PL, Neumann J, Schäfer A, Anwander A, Turner R (2012) Cortico-subthalamic white matter tract strength predicts interindividual efficacy in stopping a motor response. Neuroimage 60:370-375. CrossRef Medline

Fox MD, Halko MA, Eldaief MC, Pascual-Leone A (2012) Measuring and manipulating brain connectivity with resting state functional connectivity magnetic resonance imaging (fcMRI) and transcranial magnetic stimulation (TMS). Neuroimage 62:2232-2243. CrossRef Medline

Fox MD, Liu H, Pascual-Leone A (2013) Identification of reproducible individualized targets for treatment of depression with TMS based on intrinsic connectivity. Neuroimage 66:151-160. CrossRef Medline

Grefkes C, Nowak DA, Wang LE, Dafotakis M, Eickhoff SB, Fink GR (2010) Modulating cortical connectivity in stroke patients by rTMS assessed with fMRI and dynamic causal modeling. Neuroimage 50:233-242. CrossRef Medline

Hamada M, Hanajima R, Terao Y, Arai N, Furubayashi T, Inomata-Terada S, Yugeta A, Matsumoto H, Shirota Y, Ugawa Y (2007) Quadro-pulse stimulation is more effective than paired-pulse stimulation for plasticity induction of the human motor cortex. Clin Neurophysiol 118:2672-2682. CrossRef Medline

Hamada M, Terao Y, Hanajima R, Shirota Y, Nakatani-Enomoto S, Furubayashi T, Matsumoto H, Ugawa Y (2008) Bidirectional long-term motor cortical plasticity and metaplasticity induced by quadripulse transcranial magnetic stimulation. J Physiol 586:3927-3947. CrossRef Medline

Hanajima R, Ugawa Y, Machii K, Mochizuki H, Terao Y, Enomoto H, Furubayashi T, Shiio Y, Uesugi H, Kanazawa I (2001) Interhemispheric facilitation of the hand motor area in humans. J Physiol 531:849-859. CrossRef Medline

Hayasaka S (2013) Functional connectivity networks with and without global signal correction. Front Hum Neurosci 7:880. CrossRef Medline

Hikosaka O, Isoda M (2010) Switching from automatic to controlled behavior: cortico-basal ganglia mechanisms. Trends Cogn Sci 14:154-161. CrossRef Medline

Hsu TY, Tseng LY, Yu JX, Kuo WJ, Hung DL, Tzeng OJ, Walsh V, Muggleton NG, Juan CH (2011) Modulating inhibitory control with direct current stimulation of the superior medial frontal cortex. Neuroimage 56:22492257. CrossRef Medline

Isoda M, Hikosaka O (2008) Role for subthalamic nucleus neurons in switching from automatic to controlled eye movement. J Neurosci 28: 7209-7218. CrossRef Medline

Juan CH, Muggleton NG (2012) Brain stimulation and inhibitory control. Brain Stimul 5:63-69. CrossRef Medline

Levy BJ, Wagner AD (2011) Cognitive control and right ventrolateral prefrontal cortex: reflexive reorienting, motor inhibition, and action updating. Ann N Y Acad Sci 1224:40-62. CrossRef Medline

Li CS, Huang C, Constable RT, Sinha R (2006) Imaging response inhibition in a stop-signal task: neural correlates independent of signal monitoring and post-response processing. J Neurosci 26:186-192. CrossRef Medline
Li CS, Yan P, Sinha R, Lee TW (2008) Subcortical processes of motor response inhibition during a stop signal task. Neuroimage 41:1352-1363. CrossRef Medline

Logan GD, Cowan WB (1984) On the ability to inhibit thought and action: a theory of an act of control. Psychol Rev 91:295-327. CrossRef

Nachev P, Wydell H, O'neill K, Husain M, Kennard C (2007) The role of the pre-supplementary motor area in the control of action. Neuroimage 36 [Suppl 2]:T155-T163. CrossRef Medline

Nakamura K, Enomoto H, Hanajima R, Hamada M, Shimizu E, Kawamura Y, Sasaki T, Matsuzawa D, Sutoh C, Shirota Y, Terao Y, Ugawa Y (2011) Quadri-pulse stimulation (QPS) induced LTP/LTD was not affected by Val66Met polymorphism in the brain-derived neurotrophic factor (BDNF) gene. Neurosci Lett 487:264-267. CrossRef Medline

Nakatani-Enomoto S, Hanajima R, Hamada M, Terao Y, Matsumoto H, Shirota Y, Okabe S, Hirose M, Nakamura K, Furubayashi T, Kobayashi S, Mochizuki H, Enomoto H, Ugawa Y (2012) Bidirectional modulation of sensory cortical excitability by quadripulse magnetic stimulation (QPS) in humans. Clin Neurophysiol 123:1415-1421. CrossRef Medline

Nambu A, Tokuno H, Takada M (2002) Functional significance of the cortico-subthalamo-pallidal "hyperdirect" pathway. Neurosci Res 43: 111-117. CrossRef Medline

Nettekoven C, Volz LJ, Kutscha M, Pool EM, Rehme AK, Eickhoff SB, Fink GR, Grefkes C (2014) Dose-dependent effects of theta burst rTMS on cortical excitability and resting-state connectivity of the human motor system. J Neurosci 34:6849-6859. CrossRef Medline

Neubert FX, Mars RB, Buch ER, Olivier E, Rushworth MF (2010) Cortical and subcortical interactions during action reprogramming and their related white matter pathways. Proc Natl Acad Sci U S A 107:13240-13245. CrossRef Medline

Obeso I, Robles N, Marrón EM, Redolar-Ripoll D (2013) Dissociating the role of the pre-SMA in response inhibition and switching: a combined online and offline TMS approach. Front Hum Neurosci 7:150. CrossRef Medline

Ray NJ, Brittain JS, Holland P, Joundi RA, Stein JF, Aziz TZ, Jenkinson N (2012) The role of the subthalamic nucleus in response inhibition: evidence from local field potential recordings in the human subthalamic nucleus. Neuroimage 60:271-278. CrossRef Medline

Rossi S, Hallett M, Rossini PM, Pascual-Leone A (2009) Safety, ethical considerations, and application guidelines for the use of transcranial magnetic stimulation in clinical practice and research. Clin Neurophysiol 120:2008-2039. CrossRef Medline

Rubia K, Smith AB, Brammer MJ, Taylor E (2003) Right inferior prefrontal cortex mediates response inhibition while mesial prefrontal cortex is responsible for error detection. Neuroimage 20:351-358. CrossRef Medline

Schmidt R, Leventhal DK, Mallet N, Chen F, Berke JD (2013) Canceling actions involves a race between basal ganglia pathways. Nat Neurosci 16:1118-1124. CrossRef Medline

Shirota Y, Hamada M, Terao Y, Matsumoto H, Ohminami S, Furubayashi T, Nakatani-Enomoto S, Ugawa Y, Hanajima R (2010) Influence of shortinterval intracortical inhibition on short-interval intracortical facilitation in human primary motor cortex. J Neurophysiol 104:1382-1391. CrossRef Medline

Swann N, Tandon N, Canolty R, Ellmore TM, McEvoy LK, Dreyer S, DiSano M, Aron AR (2009) Intracranial EEG reveals a time- and frequencyspecific role for the right inferior frontal gyrus and primary motor cortex in stopping initiated responses. J Neurosci 29:12675-12685. CrossRef Medline

Swann NC, Cai W, Conner CR, Pieters TA, Claffey MP, George JS, Aron AR, Tandon N (2012) Roles for the pre-supplementary motor area and the right inferior frontal gyrus in stopping action: electrophysiological responses and functional and structural connectivity. Neuroimage 59: 2860-2870. CrossRef Medline

Swann NC, Tandon N, Pieters TA, Aron AR (2013) Intracranial electroencephalography reveals different temporal profiles for dorsal- and ventrolateral prefrontal cortex in preparing to stop action. Cereb Cortex 23: 2479-2488. CrossRef Medline

Swick D, Ashley V, Turken U (2011) Are the neural correlates of stopping and not going identical? Quantitative meta-analysis of two response inhibition tasks. Neuroimage 56:1655-1665. CrossRef Medline

Tabu H, Mima T, Aso T, Takahashi R, Fukuyama H (2011) Functional relevance of pre-supplementary motor areas for the choice to stop during Stop signal task. Neurosci Res 70:277-284. CrossRef Medline 
van der Werf YD, Sanz-Arigita EJ, Menning S, van den Heuvel OA (2010) Modulating spontaneous brain activity using repetitive transcranial magnetic stimulation. BMC Neurosci 11:145. CrossRef Medline

Van Dijk KR, Hedden T, Venkataraman A, Evans KC, Lazar SW, Buckner RL (2010) Intrinsic functional connectivity as a tool for human connectomics: theory, properties, and optimization. J Neurophysiol 103:297-321. CrossRef Medline

Verbruggen F, Aron AR, Stevens MA, Chambers CD (2010) Theta burst stimulation dissociates attention and action updating in human inferior frontal cortex. Proc Natl Acad Sci U S A 107:13966-13971. CrossRef Medline

Voytek B (2006) Emergent basal ganglia pathology within computational models. J Neurosci 26:7317-7318. CrossRef Medline

Wassermann EM (1998) Risk and safety of repetitive transcranial magnetic stimulation: report and suggested guidelines from the International Workshop on the Safety of Repetitive Transcranial Magnetic Stimulation, June 5-7, 1996. Electroencephalogr Clin Neurophysiol 108:1-16. CrossRef Medline
Watanabe T, Hanajima R, Shirota Y, Ohminami S, Tsutsumi R, Terao Y, Ugawa Y, Hirose S, Miyashita Y, Konishi S, Kunimatsu A, Ohtomo K (2014) Bidirectional effects on interhemispheric resting-state functional connectivity induced by excitatory and inhibitory repetitive transcranial magnetic stimulation. Hum Brain Mapp 35:1896-1905. CrossRef Medline

Whitfield-Gabrieli S, Nieto-Castanon A (2012) Conn: a functional connectivity toolbox for correlated and anticorrelated brain networks. Brain Connect 2:125-141. CrossRef Medline

Zandbelt BB, Bloemendaal M, Hoogendam JM, Kahn RS, Vink M (2013) Transcranial magnetic stimulation and functional MRI reveal cortical and subcortical interactions during stop-signal response inhibition. J Cogn Neurosci 25:157-174. CrossRef Medline

Zheng D, Oka T, Bokura H, Yamaguchi S (2008) The key locus of common response inhibition network for no-go and stop signals. J Cogn Neurosci 20:1434-1442. CrossRef Medline 